\title{
Proline derived ligands for the titanium-catalyzed enantioselective synthesis of propargyl alcohols in presence of diethylzinc
}

\author{
Prianka Chohan, Giovanni Barrera, Kimberly Valdivia and Parminder Kaur \\ College of Science and Health, Department of Chemistry, William Paterson University, \\ 300 Pompton Road, Wayne, NJ 07470, United States
}

Corresponding Author's Email: kaurp6@wpunj.edu, Tel: (973)-720-2706

\begin{abstract}
:
A novel titanium/proline-derived catalyst system is reported for the enantioselective synthesis of propargyl alcohols. The reaction proceeded smoothly under mild conditions with efficient reaction times. A series of proline and proline-based ligands including Lproline, L-prolinol, trans-hydroxy-L-prolinol, and substituted trans-hydroxy-L-proline derivatives were used to have a better stereocontrol on the reaction. Initially, lithium acetylide was employed to carry out the nucleophilic addition reaction, however poor reaction profile was achieved with poor enantioselectivities. When diethylzinc was used instead, high product yields (>85\%) and moderate to high enantioselectivities were achieved (68-82\%). Three different alkynes, aromatic as well as aliphatic, phenylacetylene, $n$-hexyne and 3,3-diethoxy-prop-1-yne were used to carry out the reaction with a series of different aromatic and heterocyclic aldehydes. Better reaction profiles were achieved with aromatic alkynes than with aliphatic ones.
\end{abstract}

\section{Keywords}

Proline-derived chiral ligands, Enantioselective synthesis, Propargyl Alcohols, Lewis acid catalysis

\section{Introduction}


Chiral propargyl alcohols are useful synthetic intermediates for the synthesis of various bioactive natural products and pharmaceutical compounds. Propargyl alcohols can also be very easily converted to heterocycles such as polyhydrofurans and polyhydropyrans, which are synthetically important moieties. In addition, alkyne functional group acts as a site for coupling or further derivatization, as it can be converted to aldehydes or ketones by hydration or oxidative cleavage, or olefins or alkanes by reduction. ${ }^{1-4}$ The catalytic asymmetric alkyne addition to aldehydes is the most common and straight-forward method for the synthesis of chiral propargyl alcohols. ${ }^{5}$

Therefore, in recent years, the catalytic asymmetric alkyne addition to aldehydes has drawn great amount of attention and several new and efficient enantioselective catalyst systems for various substrates have been developed.

The first ever enantioselective addition of the alkynylzinc to benzaldehyde was reported by Hoshino and co-workers in the early 1990s. The addition was achieved successfully in the presence of chiral ligand 1 with high enantioselectivity of the product. ${ }^{6}$

Later on many effective chiral catalytic systems were reported for the enantioselective addition of terminal alkynes to aldehydes. ${ }^{7-10}$ Carreira and group reported the use of (-)-N-methylephedrine in presence of $\mathrm{Zn}(\mathrm{OTf})_{2}$ as efficient system for the asymmetric alkynylation of aliphatic aldehydes. ${ }^{11}$ Later on, independent studies by $\mathrm{Pu}$ group as well as Chan group revealed that the use of BINOL derived ligands in the presence of $\mathrm{Ti}\left(\mathrm{O}^{\prime} \mathrm{Pr}\right)_{4}$ worked great for the enantioselective addition of terminal alkynes to aromatic aldehydes. ${ }^{12-13}$ This is very useful information as it can help in the design of the ligand/metal ion system as per the need of the reaction outcome. In 2002, Pu group also discovered that 1,1'-bi-2-naphthol (BINOL), in combination with $\mathrm{Ti}\left(\mathrm{O}^{\mathrm{i}} \mathrm{Pr}\right)_{4}$, was able to catalyze reactions of alkynylzinc, generating chiral propalgyl alcohols with high enantioselectivity under mild conditions. ${ }^{12 i} \mathrm{Yu}$ and coworkers have also generated aliphatic propargyl alcohols with high enantioselectivity and high yields using Ti-BINOL catalytic system. ${ }^{14}$ Although great results were obtained with the catalytic systems reported above but most of the ligands were either (-)- $N$-methylephedrine or BINOLbased ligands. ${ }^{15}$ Hence it is desirable to develop new chiral ligands to extend the scope of this important transformation. 
Other interesting and efficient chiral ligand systems such as $\beta$-sulfonamide alcohols by Chan group, ${ }^{13}$ bifunctional catalysts by Wang group ${ }^{16}$ and prophenol systems by Trost group ${ }^{9}$ was also reported for chiral propargyl alcohol synthesis. In 2010, Nakajima group developed the lithium binaphtholate based system for the addition of trimethoxysilylalkynes to aldehydes. Optically active propargyl alcohols were obtained in good to high chemical yields and enantioselectivities. ${ }^{17}$ In 2012, Mao and co-workers reported the use of $\mathrm{Zn}$-bifunctional system for the efficient enantioselective synthesis of propargyl alcohols. ${ }^{18}$ In 2014, Ulukanli and group reported the use of 3aminoquinazolinones based system for the asymmetric addition of alkynes to aldehydes. ${ }^{19}$

In the past decades, numerous studies have been reported on the use of $\mathrm{N}, \mathrm{O}$ ligands for the asymmetric synthesis such as amino alcohols and other amino acid derivatives due to their low cost and easy availability. ${ }^{20}$ Hence various secondary and tertiary amino alcohols derived from amino acids has been used as chiral ligands in presence of $\mathrm{Ti}\left(-\mathrm{O}^{\prime} \mathrm{Pr}\right)_{4}$ for the enantioselective propargyl alcohol synthesis. ${ }^{21}$ Besides this various hydroxyl sulfonamides derived from amino acids were also used as efficient systems for this asymmetric addition. ${ }^{22}$ Among the efficient N,O-based chiral ligands/catalysts, $L$-proline and its derivatives have shown great scope and efficiency in carrying out numerous asymmetric organic transformations.

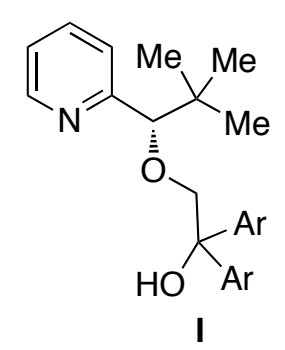<smiles>Oc1ccc2ccccc2c1-c1c(O)ccc2ccccc12</smiles>

II

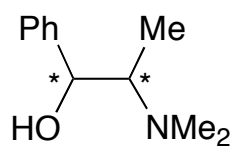

III<smiles>Oc1cc2ccccc2cc1C=NC(c1ccccc1)C(N=Cc1cc2ccccc2c(-c2c(O)ccc3ccccc23)c1O)c1ccccc1</smiles><smiles>Cc1cc(C)c(CN2CCCC2C(O)(c2ccccc2)c2ccccc2)c(C)c1</smiles> 


\section{Figure 1. Common chiral ligands reported in literature}

In the past year, our group has been focused on designing simpler chiral and nonchiral catalytic systems to carry out various organic transformations and have utilized them successfully in a variety of nucleophilic addition reactions to give variety of useful products in good yields and moderate to good enantioselectivities. ${ }^{23}$ In continuation of that work, we would like to report herein the efficient enantioselective synthesis of propargyl alcohols by the additions of metal aromatic/aliphatic acetylides onto a variety of aldehydes in the presence of proline based chiral ligands and Ti metal catalytic system.

\section{Results and Discussion}

In our initial attempt, the lithium acetylide was first generated by treating phenyl acetylene 7 with LDA in THF at $-30{ }^{\circ} \mathrm{C}$ for $1 \mathrm{~h}$. In a separate reaction tube, $\mathrm{Ti}\left(-{ }^{i} \mathrm{OPr}\right)_{4}$ was added along with the aldehyde and the chiral ligand 6 and stirred for 30 minutes. At this time, the lithium acetylide was canula transferred to reaction vessel and the reaction was allowed to run at $-10{ }^{\circ} \mathrm{C}$ for $6 \mathrm{~h}$. The reaction was constantly monitored by TLC (6:4 hexane-EtOAc) during this time but only minute product formation was observed, hence the reaction was run overnight. However, even after running the reaction for $24 \mathrm{~h}$ only $36 \%$ product was formed and a substantial amount of aldehyde was found unreacted in the crude NMR. We then tried other bases such as NaHMDS and KHMDS for the

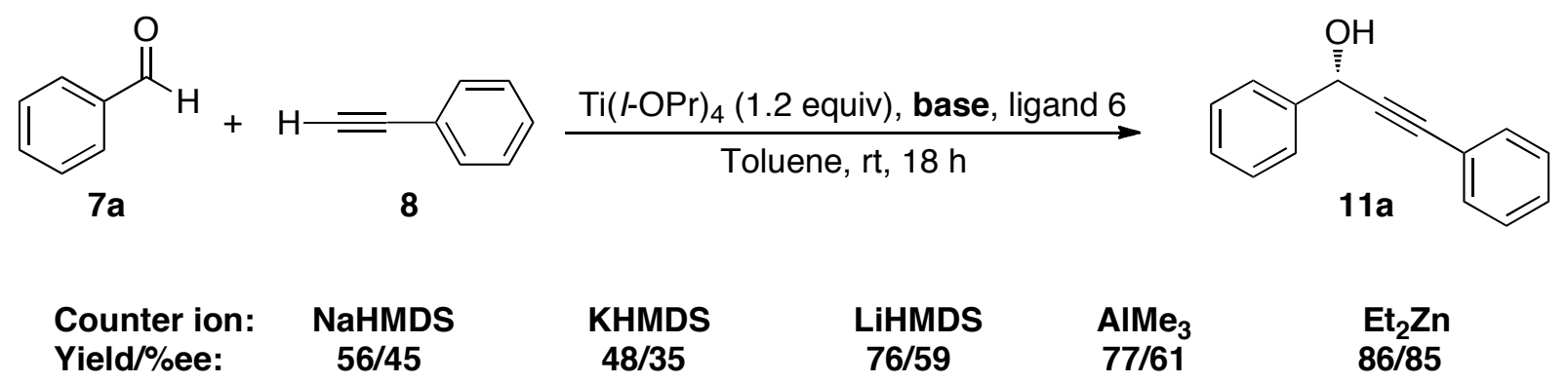

Scheme 1. Screening of different metal ions for the generation of the acetylide

acetylide formation but no promising results were obtained. The use of aluminium acetylide did not improve the reaction profile either (yield 65\%, \%ee $=45$ ) either. However, when diethylzinc was used to carry out the reaction, a much better reaction profile was achieved. The product 11a was isolated in a good yield (85\%) with good 


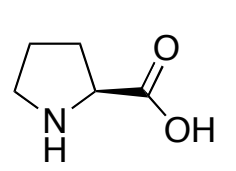

1 (35\%ee)<smiles>OC[C@H]1CCCN1</smiles>

2 (28\%ee)

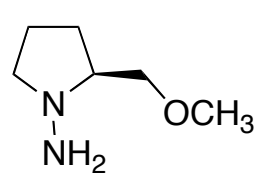

3 (25\%ee)
$\mathrm{HO}$<smiles>CC1CNC(CO)C1</smiles>

4 (34\%ee)

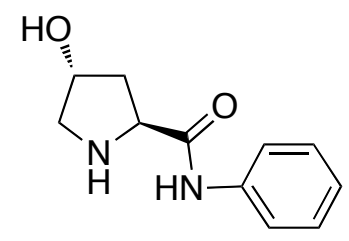

$5(32 \%$ ee)

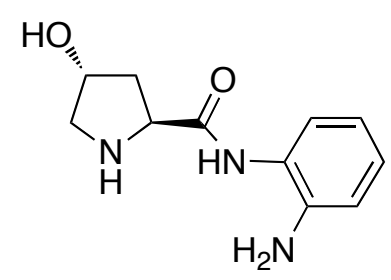

$6(85 \%$ ee)

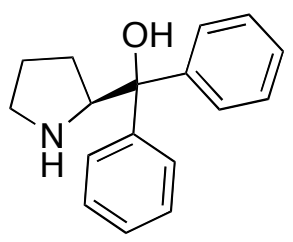

$7(43 \%$ ee $)$

Scheme 2 Ligands screened for asymmetric propargylation of aldehydes

enantioselectivity (\%ee $=85 \%)$. Based on these observations, zinc was chosen as the metal ion to generate the acetylide for the nucleophile attack (Scheme 1).

We then explored the effects of different ligands on the enantioselectivity and the overall reaction outcome. Ligands such as L-proline, trans-hydroxy proline and their derivatives listed in scheme 1 were tested. A series of optimization reactions were carried out and some of the promising results have been summarized in scheme 2 and Table 1. The presence of chiral proline derived ligands improved the enantioselectivity of the reaction. A more pronounced effect on the enantioselectivity was observed when ligand 6 was used to carry out the reaction. It was found that only low \%ee were obtained with ligands $\mathbf{4}$ and $\mathbf{5}$, due to the more flexible structure of the ligand leading to poor control on the nucleophilic attack. However, when ligand 6 was used high \%ee (85\%) was achieved. This clearly shows the importance of the diamine present in the ligand and it is anticipated that the further addition of bulk on the primary amine of the diamine can lead to further improvement in the enantiocontrol. 
Table 1. Optimization of chiral ligand, and lewis acid for the asymmetric addition of alkynylzinc to benzaldehyde ${ }^{a}$

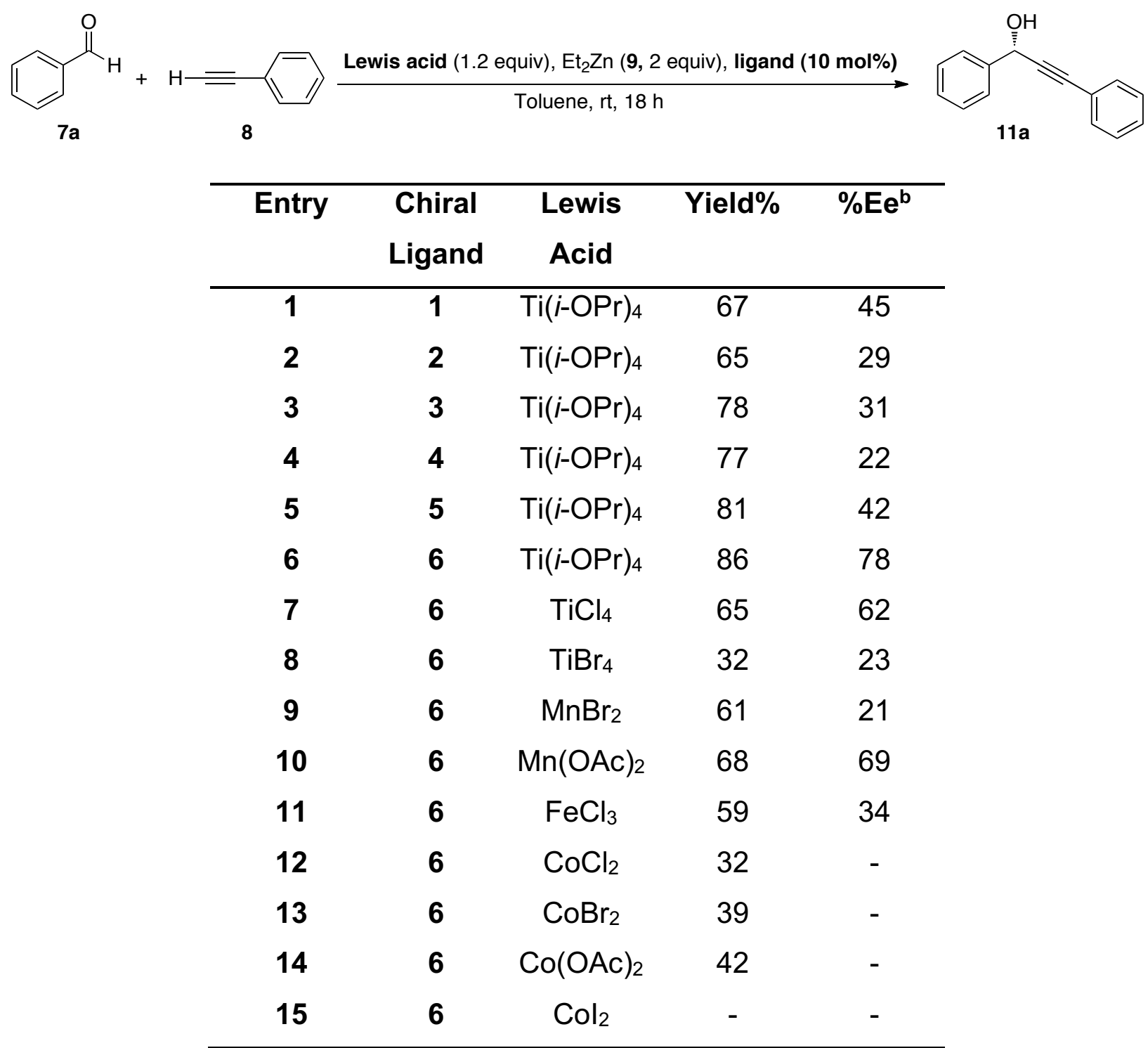

\footnotetext{
aAll reactions were carried out at room temperature with aldehyde (1.00 equiv), Ti salt (20 mol\%), chiral ligand (10 mol\%), Et $2 \mathrm{Zn}(2.0$

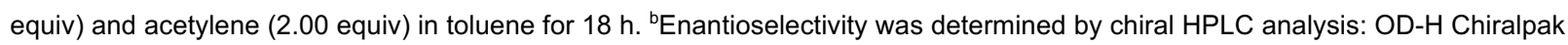
column (8:2 hexane:IPA).
}

A variety of metal salts as Lewis acids were employed during the reaction (as shown in Table 1 above). Initially, we screened various manganese salts but did not get any promising results, except with $\mathrm{MnBr}_{2}$ and $\mathrm{Mn}(\mathrm{OAc})_{2}$ (entry 9 and 10, Table 1). With $\mathrm{MnBr}_{2}$ and $\mathrm{Mn}(\mathrm{OAc})_{2}$ as catalyst, $61 \%$ and $68 \%$ yields were obtained respectively, however, poor enantioselectivities were obtained. With iron and cobalt salts also poor 
reaction profile was achieved, however when $\mathrm{Ti}$ salt $\left(\mathrm{Ti}(i-\mathrm{OPr})_{4}\right)$ (entry 6, Table 1) was used with ligand 6, good yield (86\%) and moderate selectivity $(78 \%)$ was obtained.

After getting the optimized conditions in terms of metal ion, Lewis acid and chiral ligand, we next investigated the effect of solvent and temperature on the reaction profile. Various solvents were tested including DCM, THF, DMF, toluene, acetonitrile, and 1,4dioxane. The reaction was also tested at various temperature such as $-10{ }^{\circ} \mathrm{C}, 0{ }^{\circ} \mathrm{C}$, and room temperature and after screening various temperature and different solvents, it was found that the best reaction profile was achieved with THF when reaction was started at $-10^{\circ} \mathrm{C}$ and slowly brought to room temperature. The results for the effect of solvent and temperature have been summarized in Table 2 .

Table 2. Effect of solvent and temperature on the propargylation reaction ${ }^{a}$

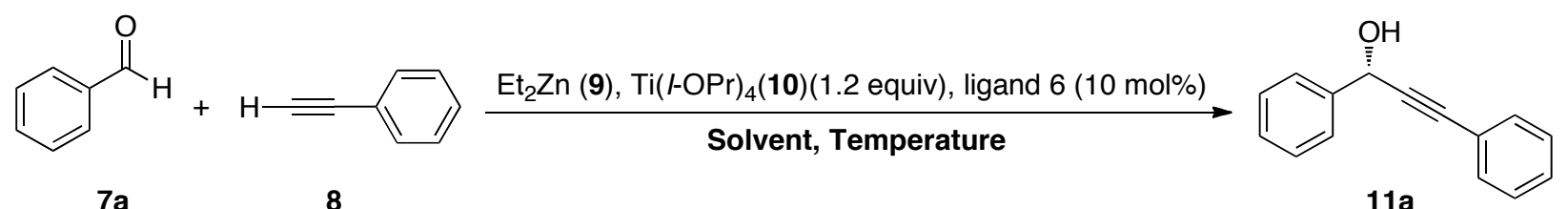

$7 \mathbf{a}$

8

11a

\begin{tabular}{|c|c|c|c|c|}
\hline Entry & Solvent & Temperature & Yield\% & $\%^{\mathbf{b}}$ \\
\hline $\mathbf{1}$ & DCM & $-10^{\circ} \mathrm{C}$ & 57 & 45 \\
& & $\mathrm{rt}$ & 65 & 32 \\
\hline $\mathbf{2}$ & THF & $-10^{\circ} \mathrm{C}$ & 56 & - \\
& & $-10^{\circ} \mathrm{C}-\mathrm{rt}$ & 70 & 49 \\
\hline $\mathbf{3}$ & Toluene & $-10^{\circ} \mathrm{C}$ & 55 & 69 \\
& & $\mathbf{r t}$ & $\mathbf{8 5}$ & $\mathbf{7 8}$ \\
\hline $\mathbf{4}$ & Acetonitrile & $-10^{\circ} \mathrm{C}$ & 56 & 22 \\
& & $-10^{\circ} \mathrm{C}$ then reflux & 59 & 38 \\
\hline $\mathbf{5}$ & $1,4-$ Dioxane & $0^{\circ} \mathrm{C}$ & 36 & 42 \\
& & $\mathrm{rt}$ & 62 & 48 \\
\hline $\mathbf{6}$ & DMF & $0^{\circ} \mathrm{C}$ & 45 & 45 \\
& & $\mathrm{rt}$ & 47 & 65 \\
\hline
\end{tabular}

${ }^{a}$ All reactions were carried out with aldehyde (1.00 equiv), Ti salt (20 mol\%), chiral ligand (10 mol\%),Et $2 \mathrm{Zn}(2.0$ equiv) and acetylene

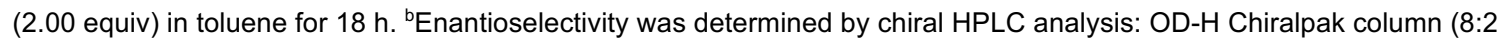
hexane:IPA). 
After establishing the best reaction conditions, the substrate scope of the titaniumchiral ligand 6 catalyzed propargylation was examined next (Table 3). Good enantioselectivities (upto $85 \%$ ee) and high yields (65-90\%) were achieved for almost all the aromatic aldehydes tested. Only $78 \%$ enantioselectivity was observed when aliphatic aldehyde was used (entry 10). However, the method demonstrated good tolerance towards a variety of functional groups such as nitro, ester, nitrile, methoxy and hydroxy. The heterocyclic aldehydes such as 2-furfuryl and 2-pyridyl were also very well tolerated.

Table 3. Asymmetric synthesis of propargyl alcohol using various aldehydes ${ }^{a}$
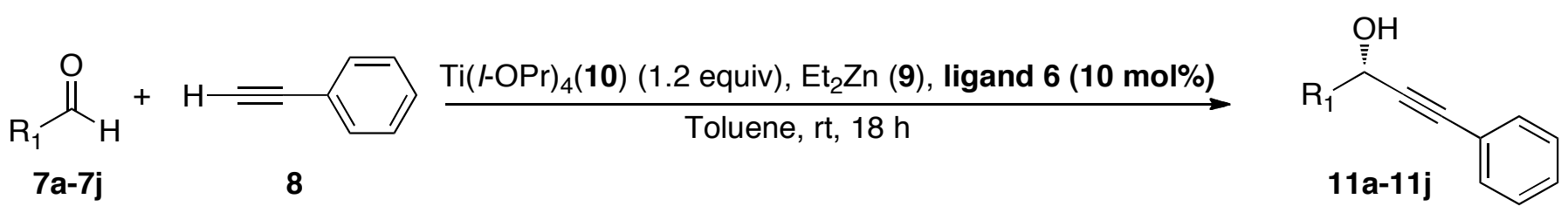

\begin{tabular}{ccccc}
\hline Entry & $\mathbf{R}_{\mathbf{1}}$ & Product & Yield\% & Ee\% $^{\mathbf{b}}$ \\
\hline $\mathbf{1}$ & Phenyl (7a) & $\mathbf{1 1 a}$ & 86 & 78 \\
$\mathbf{2}$ & 4-methylphenyl (7b) & $\mathbf{1 1 b}$ & 90 & 72 \\
$\mathbf{3}$ & 2-fluorophenyl (7c) & $\mathbf{1 1 c}$ & 75 & 67 \\
$\mathbf{4}$ & 2-bromophenyl (7d) & $\mathbf{1 1 d}$ & 92 & 76 \\
$\mathbf{5}$ & 4-methoxyphenyl (7e) & $\mathbf{1 1 e}$ & 76 & 77 \\
$\mathbf{6}$ & 2-nitrophenyl (7f) & $\mathbf{1 1 f}$ & 65 & 45 \\
$\mathbf{7}$ & 1-naphthyl (7g) & $\mathbf{1 1 g}$ & 89 & 82 \\
$\mathbf{8}$ & 2-furyl (7h) & $\mathbf{1 1 h}$ & 67 & 58 \\
$\mathbf{9}$ & 2-pyridyl (7j) & $\mathbf{1 1 i}$ & 72 & 71 \\
$\mathbf{1 0}$ & cinnamyl (7i) & $\mathbf{1 1 j}$ & 78 & 78
\end{tabular}

${ }^{a} A l l$ reactions were carried out at room temperature with aldehyde (1.00 equiv), Ti salt (20 mol\%), chiral ligand (10 mol\%), Et $\mathrm{t}_{2} \mathrm{Zn}(2.0$ equiv) and acetylene (2.00 equiv) in toluene for $18 \mathrm{~h}$. ${ }^{\mathrm{b}}$ Enantioselectivity was determined by chiral HPLC analysis: OD-H Chiralpak column (8:2 hexane:IPA).

Two aliphatic alkynes, $n$-hexyne (12a) and 3,3-diethoxy-prop-1-yne (12b), were also tested to check the scope of the alkyne substrate of the reaction. Both the alkynes reacted smoothly under the optimized conditions and high yields and good enantioselectivities were obtained with the aldehydes tested. A series of aldehydes were 
tested and the results are summarized in Table 4. A good functional group tolerance was observed with both alkyne $12 \mathrm{a}$ and $\mathbf{1 2 b}$.

Table 4. Asymmetric propargylation of aldehydes using aliphatic alkynes ${ }^{a}$

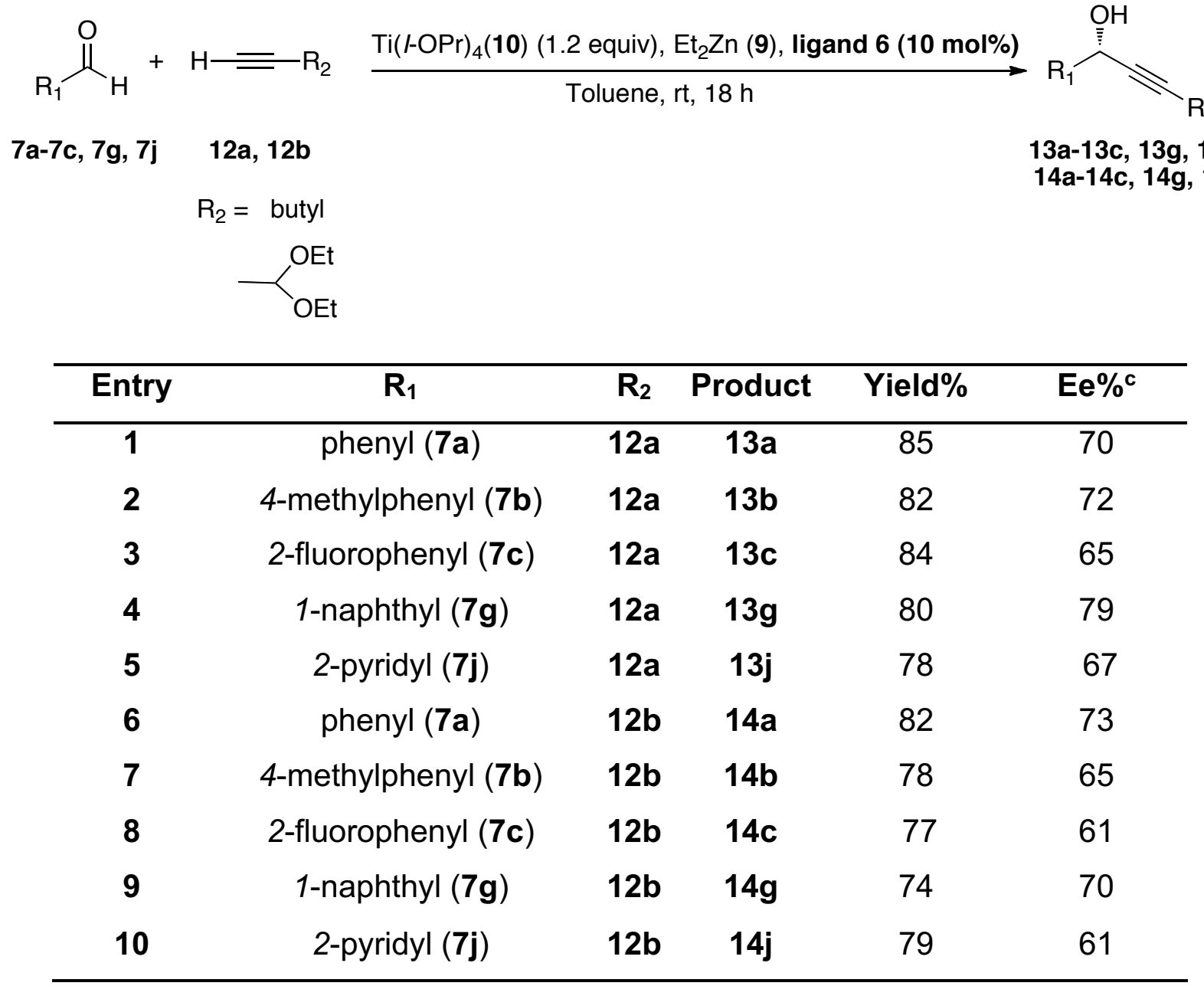

${ }^{a}$ All reactions were carried out at room temperature with aldehyde (1.00 equiv), Ti salt (20 mol\%), chiral ligand (10 mol\%),Et $2 \mathrm{Zn} \mathrm{(2.0}$ equiv) and acetylene (2.00 equiv) in tolune for $18 \mathrm{~h}$. 'Enantioselectivity was determined by chiral HPLC analysis: OD-H Chiralpak column (8:2 hexane:IPA).

The proposed transition state for the propargylation of aromatic aldehyde using phenylacetylene is shown in Figure 2. The initial step is anticipated to be the binding of the $\mathrm{Ti}\left(-\mathrm{O}^{\prime} \mathrm{Pr}\right)_{4}$ with the chrial ligand $\mathbf{6}$ and its simultaneous binding with the aldehyde to increase its electrophilicity. The in situ generated zinc phenylacetylide will be coordinating with the ligand 6 to allow a low energy TS and allow only one face for the 


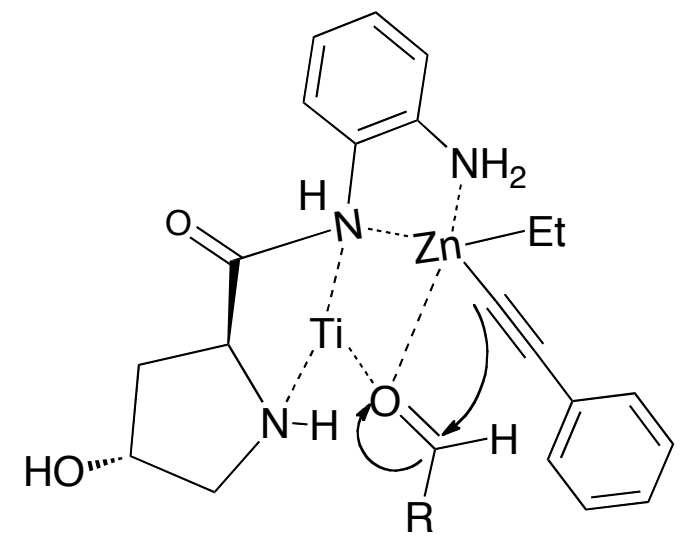

Figure 2. Proposed transition state of the reaction

nucleophile to attack the aldehyde and hence leading to the good enantio-control, which leads to the formation of the "S-configuration" of the final product. The absolute configuration of the product was assigned by comparing it with the literature reported values. ${ }^{24}$

\section{Conclusions}

A new Ti-chiral proline derived catalytic system was successfully used for the enantioselective alkynylation of aldehydes to generate enantiopure propargyl alcohols in high yields and good enantioselectivities. The design of the chiral ligand is relatively simple and hence gives an interesting method for the synthesis of chiral alcohols. The activation of the aldehyde using $\mathrm{Ti}\left(-\mathrm{O}^{\prime} \mathrm{Pr}\right)_{4}$ and coordination with the chiral ligand facilitate the zinc phenylacetylide to attack the carbonyl in a stereo controlled manner. The presence of the diamine group on the chrial ligand is found to be crucial for the stereo control demonstrated in the reaction. The reaction with all the three alkynes tested, phenylacetylene, $n$-hexyne and 3,3-diethoxy-prop-1-yne, gave moderate to good enantioselectivities and overall good yield of the desired product.

\section{Acknowledgements}

We would like to thank Department of Chemistry, College of Science and Health, William Paterson University (WPU) for providing the start-up funds. We would also like to thank WPU for providing the necessary facilities to carry out this study. C.S., D.M., H.L. and 
P.C. would like to thank Garden State-Louis Stokes Alliance for Minority Participation (GS-LSAMP) for the financial support. P.K. thanks Center for Research Summer Award, WPU and Assigned Release Time (ART), WPU for the financial assistance and the time required to perform this research.

Authors do not have any conflict of interest.

\section{References}

1. (a) Stang, P. J. and Diederich F. Modern Acetylene Chemistry, Weinheim-VCH, 1995. (b) Nicolaou, K. C.; Roschangar, F.; Vourloumis, D. Angew. Chem. Int. Ed. 1998, 37, 2014-2045.

2. Fox, M. E.; Li, C.; Marino, J. P. J.; and Overmann, L. E. J. Am. Chem. Soc. 1999, $121,5467$.

3. Corey, E. J. and Cimprich, K. A. J. Am. Chem. Soc. 1994, 116, 3151.

4. (a) Trost, B. and Krische, M. J. J. Am. Chem. Soc. 1999, 121, 6131. (b) Chen, MY. and Fang, J. M. J. Org. Chem. 1992, 57, 2937. (c) Evans, D.; Halstead, D. P. and Allison, B. D. Tetrahedron. Lett. 1999, 40, 4461. (d) Bode, J. W. and Carreira, E. M. J. Am. Chem. Soc. 2001, 123, 3611-3612. (e) Roush, W. R. and Sciotti, R. J. Am. Chem. Soc. 1994, 116, 6457.

5. Lu, G.; Li, Y. M.; Li, X. S.; Chan, A.S.C. Chem. Rev. 2005, 249, 1736. (b) Pu, L. and Yu, H.B. Chem. Rev. 2001, 101, 757. (c) Marshall, J. A. and Wang, X. J. J. Org. Chem. 1992, 57, 1242.

6. Ishizaki, M. and Hoshino, O. Tetrahedron 1994, 5, 1901.

7. (a) Yang, F.; Xi, P.; Yang, L.; Lan, J.; Xie, R. And You, J. J. Org. Chem. 2007, 72, 5457. (b) Li, Z. B. and Pu, L. Org. Lett. 2004, 6, 1065.

8. Emmerson, D. P.G.; Hems, W. P. and Davis, B. G. Org. Lett. 2006, 8, 207.

9. (a) Trost, B. M.; Weiss, A. H. and Wangelin, A. J. J. Am. Chem. Soc. 2006, 128, 8. (b) Trost, B. M.; Sieber, J.D.; Qian, W.; Dhawan, R. and Ball, Z. T. Angew. Chem. Int. Ed. Engl. 2009, 48, 5478. (c) Trost, B. M.; Chan, V.S. and Yamamoto, D. J. Am. Chem. Soc. 2010, 132, 5186.

10. Koyuncu, H. and Dogan, O. Org. Lett. 2007, 9, 3477. 
11. Anand, N. K. and Carreira, E. M. J. Am. Chem. Soc. 2001, 123, 9687.

12. (a) Moore, D. and Pu, L. Org. Lett. 2002, 4, 1855. (b) Moore, D.; Huang, W.-S.; Xu, M.-H. and Pu, L. Tetrahedron Lett. 2002, 43, 8831. (c) Xu, M.-H. and Pu, L. Org. Lett. 2002, 4, 4555. (d) Liu, L. and Pu, L. Tetrahedron 2004, 60, 7427. (e) Li, Z.-B. and Pu, L. Org. Lett. 2004, 6, 1065. (f) Yue, Y.; Turlington, M.; Yu, X.-Q. and Pu, L. J. Org. Chem. 2009, 74, 8681. (g) Pu. L.; Yu, H.-B. Chem. Rev. 2001, 101, 757824. (h) Chen, X.; Chen, W.; Wang, L.; Yu, X.-Q.; Huang, D.-S. and Pu, L. Tetrahedron 2010, 66, 1990. (i) Gao, G.; Moore, D.; Xie, R. G. and Pu, L. Org. Lett. 2002, 4, 4143-4146.

13. (a) Lu, G.; Li, X.; Chan, W. L. and Chan, A. S. Chem. Commun. 2002, 21, 172. (b) Ruan, J.; Lu, G.; Xu, L.; Li, Y.-M. and Chan, A. S. Adv. Synth. Catal. 2008, 350, 76. 14.Du, X.; Wang, Q.; He, X.; Peng, R.-G.; Zhang, X. and Yu, X.-Q. Tetrahedron: Asymmetry 2011, 22, 1142-1146.

15. Niwa, S. and Soai, K. J. Chem. Soc. Perkin Trans. I 1990, 937.

16. (a) Xu, Z.; Chen, C.; Xu, J.; Miao, M.; Yan, W. and Wang, R. Org. Lett. 2004, 6, 1193. (b) Han, Z.-J.; Da, C.-S.; Xu, Z.-Q.; Ni, M. and Wang, R. J. Mol. Cat. A 2005, 236, 32.

17. Ueda, T.; Tanaka, K.; Ichibakase, T.; Orito, Y. and Nakajima, M. Tetrahedron 2010, $66,7726$.

18. Lu, X.; Xie, G.; Li, T.; Qu, X. and Mao, J. Synthetic Communications, 2012, 42, 775. 19. Karabuga, S.; Karakaya, I. and Ulukanli, S. Tetrahedron Asymmetry, 2014, 25, 851.

20. (a) Mao, J. C.; Wan, B.S.; Wu, F. and Lu, S.W. Chirality, 2005, 17, 245. (b) Ni, M.; Wang, R.; Han, Z.-J.; Mao, B.; Da, C.S.; Liu, L. and Chen, C. Adv. Synth. Catal. 2005, 347, 1659.

21. Kang, Y. F.; Wang, R.; Liu, L.; Da, C.S.; Yan, W. J. and Xu, Z. Q. Tetrahedron Lett. 2005, 46, 863.

22. Xu, Z.; Wang, R.; Xu, J.; Da, C.; Yan, W. and Chen, C. Angew. Chem. Int. Ed. 2003, 42, 5747. 
23. (a) Datilus, V.; AbdulKarim, M.; Patrizio, A. and Kaur, P. Tetrahedron Lett. 2016, 57, 2778. (b) Lim, H.; Datilus, V.; Teriak, R.; Chohan, P. and Kaur, P. Tetrahedron Lett. 2017, 58, 1480.

24. Corey, E. J. and Cimprich, K. A. J. Am. Chem. Soc. 1994, 116, 3151. 